IRA-International Journal of Management \& Social Sciences

ISSN 2455-2267; Vol.12, Issue 01 (July 2018)

Pg. no. 1-11.

Institute of Research Advances

http://research-advances.org/index.php/RAJMSS

\title{
Cockroach Theory of Organizational Sustainability and Scalability - Detailed Study on Evidence Based on BOP Approach
}

\author{
Keerthan Raj ${ }^{1}$ \& P. S. Aithal ${ }^{2}$ \\ ${ }^{1,2}$ Srinivas Institute of Management Studies, Srinivas University, Mangalore - 575 001. INDIA.
}

Type of Review: Peer Reviewed.

DOI: http://dx.doi.org/10.21013/jmss.v12.n1.p1

\section{How to cite this paper:}

Aithal, P.S., Raj, K. (2018). Cockroach Theory of Organizational Sustainability and Scalability - Detailed Study on Evidence Based on BOP Approach. IRA-International Journal of Management \& Social Sciences (ISSN 2455-2267), 12(1), 1-11. doi:http://dx.doi.org/10.21013/jmss.v12.n1.p1

(C) Institute of Research Advances.

(cc) BY-NC

This work is licensed under a Creative Commons Attribution-Non Commercial 4.0 International License subject to proper citation to the publication source of the work.

Disclaimer: The scholarly papers as reviewed and published by the Institute of Research Advances (IRA) are the views and opinions of their respective authors and are not the views or opinions of the IRA. The IRA disclaims of any harm or loss caused due to the published content to any party.

Institute of Research Advances is an institutional publisher member of Publishers Inter Linking Association Inc. (PILA-CrossRef), USA. The institute is an institutional signatory to the Budapest Open Access Initiative, Hungary advocating the open access of scientific and scholarly knowledge. The Institute is a registered content provider under Open Access Initiative Protocol for Metadata Harvesting (OAI-PMH).

The journal is indexed \& included in WorldCat Discovery Service (USA), CrossRef Metadata Search (USA), WorldCat (USA), OCLC (USA), Open J-Gate (India), EZB (Germany) Scilit (Switzerland), Airiti (China), Bielefeld Academic Search Engine (BASE) of Bielefeld University, Germany, PKP Index of Simon Fraser University, Canada. 


\begin{abstract}
The question of survival and sustenance are at the very foundation of every individual or organization. There are various factors that are essential for growth and sustenance of companies. There has been many research studies undertaken to gauge the success factors or to breakdown the components and study success in detail. Especially so, it gains even more importance when companies are serving the markets where consumers have very low incomes and have several unmet needs. Companies serving the base of the pyramid markets need relatively unique strategies and value propositions for success. The base of pyramid came into forefront when management thinkers $C K$ Prahalad and Staurt L. Hart, formulated the "Bottom of the Pyramid" theory in a 2002 article about how businesses can help the poor while still able to make a profit. They noted that there was little competition among the millions of the poor, who essentially live in a world of non consumption. Through low prices, new business models and innovative products, and inclusive value creation corporations along with the help of nongovernmental organizations (NGOs) and local governments, could make money and do good for the larger cause by tapping this underserved market. It has been the belief of many that BOP consumers are typically characterized by several unmet needs, it could range from food, sanitation, transport, communication, and connectivity. It is also interesting to note that in several BOP markets where are overlapping needs not necessarily following the need hierarchy. Information and communication technology businesses have been able to occupy a larger share of the BOP consumer's wallet than even basic needs such as sanitation or electricity. What then prompts these consumers and how can businesses reach out to these segments in a phased successful manner. This paper develops the concept, postulates, explanations, theoretical model, and business case based proof on Cockroach Theory of Organizational sustainability and scalability by considering BOP business companies performance evidence. The study also discusses the applicability of this theory and its frameworks on companies and their business models focusing on BOP sectors along with the limitations.
\end{abstract}

Keywords: Bottom of the pyramid (BOP), Survival, Sustenance, Cockroach theory.

\title{
Introduction
}

'Sustainability', a simple definition of the term would fetch the meaning as, "the ability to be maintained at a certain rate or level. In the last decade, the word has attained higher usage due to the increased importance individuals, firms, large corporations, governments, global economies are placing on the orientation of all activities aimed to enhance current and future potential of society, it can be termed as a process predominantly characterized by the pursuit of an ideal. Today, aiming at sustainable development has become a need in the light of depleting resources, environmental degradation, and a uniform human ecosystem creation. The environment, society, and economy have been considered to be the cornerstones of any discussion on sustainability. More conclusively, as per some thinkers sustainability implies responsible and proactive decision-making. As the term itself can be read as - sustain-ability, it calls for ideas, thoughts, strategies, focus around sustenance. For our discussion on doing businesses successfully in the base of the pyramid, markets sustainability is based on the premise of being able to continue to serve the low income markets and emerging markets. Especially for many companies which are flourishing financially through continued commercial success may overtime be unsustainable. Even though they might make laudable efforts to venture into virgin terrains like the low income markets, only reducing serving sizes or using renewable energy sources or green product engineering may not ensure their commercial success. It is essential then to understand what drives sustainability.

Every organization wants to scale fast and grow rapidly, at the same time it is imperative that the business creates sustainable value not only for the establishments in concern but also for the society at large. The quest for wealth by serving the base of the pyramid markets was brought into focus when management thinkers C K Prahalad and S L Hart wrote about the proposition almost two decades back. Since then, many multinationals and large domestic corporations have seen profitable opportunities in serving the world's largest market of more than four billion population. This segment has been largely ignored or overlooked because of the large presence of the informal unorganized sector in this market [1-4]. Hence it is surmounted by issues such as lack of knowledge, poor literacy, unattractive income levels, and tightly bound closed door communities. These bottlenecks make the entry and operational issues seem more difficult. Building sustainable and scalable businesses in unknown volatile terrains are 
not easy and there are bound to be a lot of learning's involved. Over a period of time, these learning have been studied and certain best practices have been identified to enter and thrive in certain markets and uncertain terrains.

Introduction about BOP - The bottom of the pyramid (BOP) approach as propounded by C.K. Prahalad and Stuart L. Hart in 'The Fortune at the Bottom of the Pyramid' (2002) [2] used the 4-tiered pyramid to represent the global distribution of wealth and the capacity to generate income. Right at the top of the world economic pyramid are 75 to 100 million affluent Tier I consumers from around the world [7, 8]. This is a cosmopolitan group composed of middle- and upper-income people in developed countries and the few rich elites from the developing world. In the middle of the pyramid, in Tiers 2 and 3, are poor customers in developed nations and the rising middle classes in developing countries, the targets of MNCs ${ }^{c}$ past emerging-market strategies. They categorized 4 billion people in Tier 4 i.e. at the bottom of the pyramid. Their annual per capita income based on purchasing power parity in U.S. dollars is less than $\$ 1,500$, the minimum considered necessary to sustain a decent life. For well over a billion people roughly one-sixth of humanity per capita income is less than $\$ 1$ per day $[6,14]$.

As per World Bank projections, the population at the bottom of the pyramid could swell to more than 6 billion people over the next 40 years, this is due to the fact that the bulk of the world's population growth occurs there. Most Tier 4 people live in rural villages, or urban slums and shantytowns, and they usually do not hold legal title or deed to their assets (e.g., dwellings, farms, businesses).

Table 1 - The World Economic Pyramid

\begin{tabular}{|ccc|}
\hline Annual Per Capita Income* & Tiers & Population in Millions \\
\hline More Than $\$ 20,000$ & 1 & $75-100$ \\
\hline$\$ 1,500-\$ 20,000$ & $2 \& 3$ & $1,500-1,750$ \\
\hline Less Than $\$ 1,500$ & 4 & 4,000 \\
\hline
\end{tabular}

* Based on purchasinq pawer parily in US\$

Source: U.N. World Development Reports (Adapted from Prahalad \& Hart, 2002 [3])

Most people who earn less than $\$ 2$ per a day are categorized as Tier 4 , and live mostly in the under developed countries, here they dwell in rural villages and shanty towns. Prahalad and Hart were of the opinion that the private sector and specifically large multinationals participation in this sector was central to transforming the poor into consumers. They argue that multinationals by serving this bottom of the pyramid segment would not only contribute towards global poverty eradication but can create employment opportunities in local markets while generating profits for themselves in a multitrillion dollar market segment. It is estimated that the BOP population in most of the countries are not integrated into the global market economy and generally do not stand to benefit from it. The World Resources Institute figures estimate that close to one billion of this population have incomes of less than \$ 1 per day (in local purchasing power) irrespective of the country [3]. Integrating this population into the global market economy cannot be left to the task of aid agencies and the governments. Hence it is imperative that companies embrace this segment in a strategized manner as a formal market for their goods and services.

Business opportunities to serve BOP sector - Low income is not no income. The base of the pyramid markets was ignored for a large part of the $21^{\text {st }}$ century by global corporations while looking at opportunities to expand market outside of their home turf. Interestingly while a majority of the global population lives outside of the west, corporations had been looking at creamy layers of the consumers in developing countries such as Asia, Africa, and South America and so on. While there were efforts to scale and sustain in developing countries they tended to focus only on the higher income category of consumes, since the masses were low income and they are typically characterized by living a sustenance livelihood. This meant that the little income was primarily meant for addressing 
the basic needs [1-5]. Organizations were not looking at an opportunity to fulfill these basic needs itself by scaling their operations and looking at diverse strategies. The traditional approach to 'serving base of pyramid markets' was from a charity and public aid perspective. The population in this segment was deemed to be too poor to help themselves and external agencies thus had to provide relief measures as a public good service. As a result, the efforts was directed towards providing necessities such as basic healthcare, access to clean water and other basic necessities such as sanitation.

In the aftermath of the proposition by Prahald and Hart, the traditional approach paved the way for a more business oriented market based approach - this was built on the premise that even the poorest of the poor had an income or could trade labour. The focus was on people as consumers or producers and not just mere beneficiaries'. Many multinationals and large corporations understood this approach and built strategies focused on making these low income consumer markets competitive, inclusive and efficient. The major successes in a market approach to the BOP community can be seen from major sectors in India - FMCG, financial services and ICT. While predominantly most market based BOP entries start by focusing on basic needs such as water, healthcare and other basic needs, it has to be understood that BOP consumers also have the same needs of food, clothing, and transportation. The World Resources Institute had undertaken an exhaustive research based on income data from 110 countries, into BOP market size and components of the consumer basket and it has been found that by and large the most significant share of the expense pie is taken up by food, followed by energy, housing, transportation, healthcare information and communication technologies (ICT) and other needs.[1,18] Some of the successful companies who have made great inroads into emerging markets are Unilever, the India subsidiary of the multinational- Hindustan Unilever Limited has seen phenomenal scale and growth by being BOP focused and co partnering with the local communities as business drivers with income earning opportunities. Another domestic FMCG giant in India, Nirma which predominantly sells detergents and washing cakes in rural and BOP sectors has been a pioneer which in fact inspired many FMCG multinationals to realize the potential of the BOP segment in India. ITC Ltd was started in 1910 (as Imperial Tobacco Company India Limited and went on to become ITC Ltd after they diversified into FMCG, Hotel industry, Information Technology) and the core business was cigarette manufacturing. In the last five decades ITC has diversified to be one of the top five players in the FMCG sector in India. ITC is also one of the earliest companies to partner with local farmers and people from the BOP communities to co create products, they used innovative 'choupals', which was informal gatherings of villagers from surrounding locations where they could meet and discuss issues pertaining their occupations. ITC provided kiosks which would give details on agricultural crops, rainfall forecasts, and advice on crops to be grown, eliminating middlemen and making the crop selling process easier, going forward ITC used the services of these communities of predominantly agrarian population to grow oils seeds which would be bought back by ITC for its edible oil business. When farmers became members of these chouplas ITC took care to ensure that they provided warehouses for storage, and there was complete transparency and immediate payments made to farmers which made their lives easier especially the small farmers who were looted by middlemen earlier. ITC eventually created hyper marts (included all products right from a matchbox to a motorbike) in certain large villages which ensured that their products were well accepted and the community and company were in a win - win arrangement.

The second most well accepted and adopted product for the BOP in India is financial services. While we need to remember that the BOP segment is characterized by an informal economy where a major portion of the transactions are cash based, most consumers are without any identity documents and lack of banking habits. However, microfinance institutions have been very successful in getting a firm foot on the ground as far as small finances are concerned. Firms started as back as 1997 SKS Microfinance (now Bharath Financial Inclusion Limited, BFIL), Share Microfinance Limted (1998), Shri Kshetra Dharmashthala Rural Development Project (1991) all usually have a member contingent as large as 20,000 to 30,000 spread across more than 500 branches across India, they have been very aggressive in small lending to low income population especially those who could not approach banks and were being exploited by local money lenders. Even multinationals like HUL, P\&G etc tied up with some microfinance institutions to provide finance to their community salespersons and partner to sell their products. The third major segment is Information and Communication Technology (ICT). Pioneers such as Airtel, Reliance Communications and recently Reliance Telecom have focussed at the BOP segment. Reliance Communications launched in 2003-04 their ambitious CDMA handsets at a mere INR 500 through which they were able to capture the low income market in a span of two months. Especially in the BOP communities in Indian and many other countries, it has been seen 
that as per statistics that ICT penetration and acceptability is very high. Most companies like Celtel in Africa and Reliance Communication earlier and Reliance Telecom recently, in India have succeeded by creating hybrid products for the segment, franchise agents, and small credit facilities. They have seen success and scale by involving buyers as sellers in all of the product suites.

\section{Objectives}

(1) To study the successful strategies used by companies who have been able to make companies advancing inroads into BOP markets.

(2) To develop a theory to create a roadmap of time tested strategies for other companies on factors that need to be practiced to create sustainable and scalable growth.

\section{Background to the Proposal}

The Cockroach theory (named after Cockroach - an insect synonymous with indestructible features that enable sustainability and growth) has been attributed to certain features of the cockroach that can be compared to be the key factors for sustainable and scalable growth in BOP markets, these are as follows [14 ] -

(1) Cockroaches have Feelers - these enable them to feel and smell, being highly alert and sensing any situation that could be a danger or threat.

(2) Molting - Cockroaches have the amazing capability to molt and regrow a lost limb. In many situations heavy losses may occur to business, strategies may incur high costs with no profits, operations, and businesses should have the tenacity to bear the loss and regrow lost opportunities. In dull phases, they will stay discreet and reappear with renewed ideas and strategies [14].

(3) Sustainability - An amazing feature is that a headless cockroach can live for several days because it breathes through its sides, not through nose or mouth. Business especially those embarking or having embarked to BOP segments and emerging economies will suffer a severe paucity of information. Even firms that have done years of ground research have failed miserably at times. Businesses need to sustain through the tough times because primary and secondary data cannot compensate for on the ground experience at a larger scale.

(4) It has 3 pairs of legs - Almost all creatures of the insect family have three pairs of legs, every business has an open opportunity to tap the largest consumer base in the world. They can move over any territory or terrain but like the cockroach which is characterized by the fact that groups of cockroaches make collective decisions, similarly, businesses have to use their collective information and take strategic decisions. The stakeholders, management, directors, administrative body, operational staff, everybody has to be involved right from top to bottom and a cohesive model that embarks being in the community as a part of it since a long time. Every move needs to be incorporated into a collaborative interdependence, like how cockroaches always live cohesively in groups only. Creating interdependence right at the lowest link of the value chain is critical for boosting margins and enhancing customer conversion. This, in turn, ensures that BOP consumers will feel a sense of ownership in business development with community co-creation.

(5) Indestructibility - These creatures are blessed with a tough exoskeleton making them seemingly indestructible. Multinationals or large domestic corporations that venture to serve BOP markets need to be armoured with a tough skin. New markets and new terrains are not for the weak in any internal resource. A lot of investment and gestation is needed to start generating wealth in these markets. Certain strategies may create initial buzz and provide returns to distributors or break even profits but to sustain and scale the business constant reinventing and rethinking strategies are needed which may also fail at certain times [14].

(6) Cockroaches are Omnivores - They will eat almost anything to survive. For building large scales of businesses in emerging economies especially in the BOP sectors, the important factor is to be able to digest all shortcomings that can come along the way and use these as food to sustain. Organizations need to have a keen understanding and be prepared at all times for strategic changes because the BOP markets are not homogenous. In a country like India, there is great heterogeneity, shaping strategies suiting to the surroundings and then adapting it to the local conditions. (7) Scalability - Cockroaches fit into extremely small spaces. It is very important like the cockroach to be as discreet as possible in a way that the communities perceive these businesses, people, and offerings as one of their own. They outlive humans even in the event of a full scale nuclear war; this is probably the biggest challenge to scale to a great extent. It is not possible to do so with one gigantic decision, it is a community we are talking about, the strategies itself should slowly grow out discreetly from one success to the next, the strategy that any successful multinational or 
corporation has not come put a single step, several successful experiments have led to small success that have been built upon to scale businesses. All along the way, there has been a constant exercise of creating a sustainable business by creating products, strategies, and practices that have the ability to provide an opportunity to the BOP consumer to increase his quality of life.

\section{Postulates}

(1) Serving the world poorest need not be termed as an exercise in charity.

(2) Innovation is the key for reaching out to unventured markets.

(3) Consumers in BOP look for opportunities within their means to improve their quality of life.

(4) Companies have to enable access to consumers.

(5) Localized Value creation is critical.

(6) BOP consumers have traditionally been burdened by a BOP penalty.

(7) Need fulfillment of BOP consumers need not necessarily follow a need hierarchy.

(8) Sustainable value creation can only be successful through unconventional partnerships.

(9) BOP markets are characterized by a dead capital.

(10) Significant portion of BOP income comes from activities and sources which are only indirectly reflected in national income statistics.

\section{Explanation of Postulates}

1) Serving the world poorest need not be termed as an exercise in charity - a couple of decades back, the general assumption by most corporations that serving or doing business in the low income markets profitably was not possible. They would either approach these markets via their charitable foundations or it was considered to be the task of aid agencies and local governments. It was after the 2002 paper by Prahald and Hart that served as an eye opener and showed ample cases and opportunities to make profits in these markets.

2) BOP consumers have traditionally been burdened by a BOP penalty - BOP markets are characterized by low incomes and lack of products and services. Most of the times, these products and services are sold by local traders and vendors at exorbitant prices. There high prices, low quality of products or no products available at all. For instance, loans offered by local money lenders at exorbitant interest rates, a local trader would be seen selling adulterated loosely packed tea powder at a much higher price than what a giant FMCG could provide.

3) BOP markets are characterized by a 'dead capital' - BOP consumers are owners of informal properties and businesses, they usually may not have legal title to the place, they might be operating out of makeshift outlets which accounts for 'dead capital'. If systems are made more functional to serve this usually illiterate, category this dead capital could be accounted for in the nation's assets.

4) Significant portion of BOP income comes from activities and sources which are only indirectly reflected in national income statistics - as the primary occupation as studied by various research organizations reveals the base of pyramid consumers are in most cases in an informal cash based economy, they earn a livelihood out of odd jobs as daily wage earners, house maids, cleaners etc. They do not possess any banking facilities and since this economy is predominantly cash based the BOP incomes are not directly reflected in the GDP of a nation.

5) Innovation is the key for reaching out to unventured markets - There have been many failures by companies in reaching out and doing businesses in these markets successfully, but what is key is innovative out of the box strategies and practices that bear result.

6) Consumers in BOP look for opportunities within their means to improve their quality of life - BOP consumers are not sitting ducks for multinationals and large domestic players, though there is lack of education and information sources, they make careful decisions. If there is a gain for them they would opt to purchase that product or service, BOP consumers are not impulsive decision makers.

7) Companies have to enable access to consumers - BOP markets are characterized by lack of access it could be basic needs, infrastructure, communication, good quality products and services sometimes created by companies not wanting to venture to these territories.

8) Localized Value creation is critical - it is very essential that BOP consumers see a value in the products and services offered to them. They have limited means and the opportunity cost of acquiring various goods is 
influenced markedly by value creation and their involvement in the creation process or some economic gains from the same.

9) Need fulfilment of BOP consumers need not necessarily follow a need hierarchy - BOP consumers need not necessarily be driven by the need hierarchy in that order little income obviously means there is some limited means to acquire sources of need and want. In BOP communities in Asia, and Africa it has been seen that even though certain lower order needs may be unsatisfied, BOP consumers spend on quality education for their children, jewellery for marriage and such other higher order more pressing needs within their circumstances of culture and society.

10) Sustainable value creation can only be successful through unconventional partnerships - Since BOP consumers attempt to see a value creation and are looking for opportunities to improve their quality of life, co-creation strategies and partnerships with BOP community can help make inroads to untapped and underserved communities.

\section{Theoretical Model:}

To sustain and grow in BOP markets in emerging economies some of the key success factors [14] are listed below-

1. Community benefit Model - Any market entry mode in today's circumstances has to be an adaptive model where there is peaceful co-existence for the community and the corporation. The business has to create value for the community and improve the standard and quality of life for the people of the BOP market. It could be the most simplest product or the most complex technology oriented product but if there is no community involvement in the creation exercise or benefits that arise to the communities at large it is bound to fail or will only be a short lived phenomena.

2. Collaborative Value Partnerships - For multinationals that enter low income markets with diverse products and technologies to suit the market needs a big risk arises because of unenforceable legal mechanisms to protect their internal resources and capabilities such as patents, brands and contracts. At this juncture the sustainable model would be to enter into collaborative partnerships with local firma or domestic players. This will give them the advantage of ease of adoption to domestic legalities and enforceable legal contracts to protect copyright and knowledge transfers that may be required. These partnerships should create value for both the parties involved; there have been cases where too heavy dependence on local partners expertise has failed business growth $[1,14]$. The expertise of local partners has to be sought for building social infrastructure and local legitimacy.

3. Leverage on global strengths - While partnering locally and co-creation are the key success elements, they have to be worked along with leveraging on global expertise that the multinational or large corporations have built over the years. Certain best practices that have been tried and tested over the years can be adapted to suit local conditions and strength drawn out of this global expertise [14]. But in many cases where firms have relied on existing technology, products, partners, distribution models can call for doom. This expertise necessarily needs to be adapted to local conditions with involvement of local community and this model has to have a long term strategy to give scale to the operations. In many cases, initial successes have created internal cannibalization of distribution models and local communities have been negatively affected by this move, any strategy adopted has to be scalable in the same manner with local involvement.

4. Local Resource Sharing- Most BOP markets have non-governmental organizations and aided insinuations' trying to create fabrics of support for local communities and this fabric is upset by multinationals when they enter these markets. They need to make discreet movements so as not to upset the existing coexistence but incorporate themselves silently into this market. Local resources and capabilities have to be built by sharing resources and knowledge. These markets are characterized by social contracts, shared users of various assets and informal rules hence corporations need to focus on building inclusiveness and sharing of critical resources be it knowledge, know how, socio cultural systems and subsystems. 


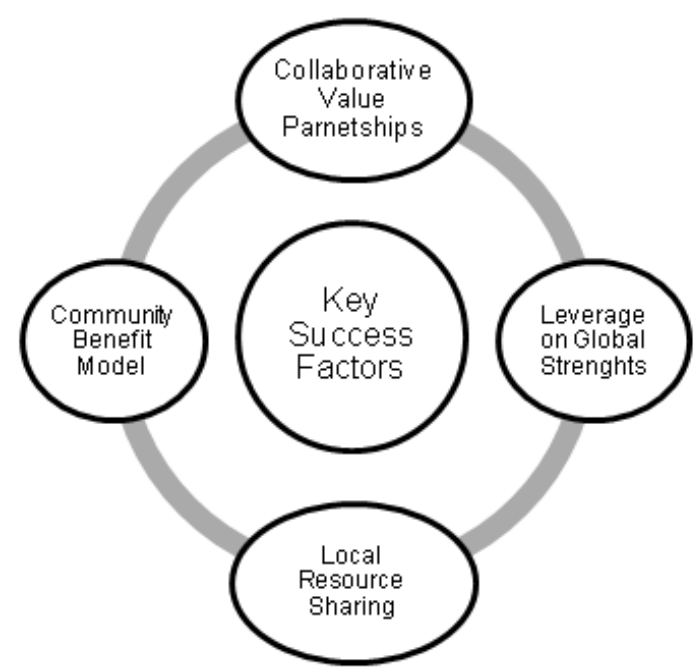

Fig 1: Key Success Factors for sustainable and scalable growth in BOP Markets [14]

Most of the thinkers on sustainable businesses or on base of the pyramid markets theorists also have propounded scalability and building sustainable businesses in base of the pyramid requires innovative strategies that focus on sustainable environmentally and community friendly value chain creations that elucidate capability generation over time and in a sustained manner. Socially embeddedness is what will drive deep rooted business growth and sustenance.

In the "The Cockroach Theory" or the "Theory of Sustainable \& Scalable growth" we have drawn a parallel between the cockroach and organization efforts to sustain and scale in BOP markets for the simple reason that scalability requires time and cockroach have been in existence as far back as 320 million years, and they have been able to outlive humans even in nuclear wars, they are creatures that have been aggressively adapting to the surroundings around them and can survive even in extremes of weather. Sustainability requires adaptability; this quality enables them to find ways to survive in most environments. Though they have not been endowed with any special feature, they have been able to survive very discreetly over long periods of time. Companies have to be keen to co-exist and adapt to circumstances' if they have to survive in economically backward developing countries or emerging markets where the obvious attractiveness might be low [14]. They have to constantly gauge the situation around them and react to these changes, strategize in groups and take collective decisions. The most important aspect, especially for our discussion on BOP segments in emerging markets is the critical criteria of success being co-existence [1-6]. Multinationals and corporations have been able to succeed only when they have realized the need to co-create and co-exist with the community and this has given them scalable sustainable growth and acceptance in these markets [12-13].

\section{Applicability}

There are several case studies [9-11] of corporations that have been successfully sustained their businesses in the BOP sector by embracing innovative partnership strategies, co-partnering.

1. HUL - By co-partnering innovatively with community members, through the wide spread Shakti Project, HUL was able to enter right into the BOP heartlands of the Indian markets. HUL was able to counter two objectives simultaneously, one was widespread acceptability since they were using people from within the same communities as sales persons and two, a value creation which was perceivable by the community. Company officers lived in these villages to understand the lives of the people they would be selling to. By partnering with HUL to sell its products or grow produce which would be bought back all led to economic well being and an enhanced value creation for the BOP communities. It ensured that the strategy was scalable and sustainable, of course, HUL had to devise newer ways of ensuring that they could scale the Shathi model without affecting their distribution network negatively. 
2. SELCO - A bright light in the dim world of the BOP world, is SELCO, which is an Indian based company founded in 1995 by Dr. Harish Hande, having started with a negligible capital they have managed to light up more than 100,000 rural homes and institutions. The task was very difficult since the rural poor were not in a position to pay the annual maintenance charges. Then SELCO relentlessly worked trying to get financial assistance to the rural poor for buying this solar lighting. For success in this business it requires continued adaptation and constant lookout for opportunities because same strategies may not be viable in another Sate. For SELCO, their tie ups with grameena bank in one state of India meant success only there. Going forward to another State was a new task altogether requiring new tie ups and new ideas.

3. D- Lite - Another successful world leader, operating in 62 countries in solar lighting business, founded by Sam Goldman and Ned Tozun in 2006, has impacted over 83 million lives so far. It has seen success in countries like India by its strategic partnerships with local microfinance companies and using local community for sales. And they have adapted to local market conditions and requirements.

4. ITC - ITC become a formidable top five in the FMCG industry in India by being one of the earliest companies to co-partner with farmers to grow oil seeds for its edible oil manufacturing unit. Setting up their own hyper mart stores and providing kiosks for farmers, storage facilitates to store their produce and subsequent purchase and timely well researched information relating to agriculture etc were part of strategies to build collaborative relationships.

5. Godrej - Godrej is a diversified businesses company of more than 100 years like ITC, and are leaders in safety lock and metal high gauge cupboard businesses. In 2013, led by the company Vice President of corporate development ventured into disruptive innovation after the first launch of an inexpensive, thermoelectric refrigeration device was unsuccessful. The team was able to unlearn and discovery product innovations and partnerships that were critical for success and Godrej 'Chotukool' was able to capture the low income market which so far had a void in the refrigeration space. These are products that are predominantly not considered necessary for the BOP but if created right and sold using the right strategies they will create a vast new market.

\section{Limitations:}

The limitations of this study would be a time constraint and certain BOP markets that have seen failures of certain co-partnering, value creation studies. The failures may have been to a variety of causes inherent to the company, its decisions or strategies to give up certain ventures entirely after initial failures. While we discuss sustainability, the sustenance cannot come with any one single way of doing things. Sustainability is a cohesive decision making exercise that comes after a period of initial bottlenecks and failures for any organization or individual.

\section{Comparison with Other Theories}

(1) With Theory of Firm - The earliest theory of the firm was founded in neoclassical economics that states that firms exist and make decisions to make profits. The business of any given entity is said to be driven by profit maximization motive. Dictated by a market economy, profit maximization was considered a rational approach for any firm in business. Going forward there were several economists who developed that theory to include transaction costs, giving due property rights, assignment of ownership and management and its affects. While the theory of the firm and modern takes on the theory of the firms sometimes distinguish amongst long term goals such as sustainability and short run goals such as profit maximization. The other theories of the firm, rested on the optimization concept. Baumol suggested managers maximize sales revenue and Marris suggested maximization of growth. In their book, A Behavioral Theory of the Firm (1963) Cyert and March [19] have studied that bureaucratic structure of the firm and the nature of interrelationships of its various parts. They postulate that the form in most cases will be pursuing five goals - production goal, inventory goal, sales goal, market share goal and profit goal. It postulates these goal maximizations [17].

These earlier theories have looked at a firm and its rationale from a predominantly economic perspective. But, as Prahalad and Hart had advocated, there is a vast population at the base of the pyramid which most corporations will tend to ignore if the opportunity is not shown in the light of the ability to gain a larger market share albeit with a longer gestation period. Hence the need for a theory which focuses primarily on what forms can do and need to do to succeed and sustain in BOP markets.

(2) With Complex theory of Sustainability - It has its foundations in systems theory [15-16], cybernetics, theory of autopoiesis, computational genetic algorithms, dissipative self-organization, deterministic chaos theory and fractals 
- complexity theory [17] originated towards the end of the twentieth century in the aftermath of the recognition by groups of scientists that certain systems were dynamic, complex and far from equilibrium. These systems came to be known as complex systems. In complex systems, there are several dynamically interacting parts, wherein the macrolevel patterns of behaviour emerge from micro-level interactions of parts or agents. It was considered that, complex systems were intelligent and capable of adapting to their environment hence they were termed as complex adaptive systems .Characteristic properties common to complex adaptive systems include the presence of simple agents following simple rules relative to the whole system - networks of agents acting with individual knowledge capacities and behavioural rules at micro levels result in outcomes that demonstrate higher coordination and collective intelligence than the sum of individual knowledge at macro levels [17]. However, the world is very complex and a difficult to understand set of systems and subsystems exist within each diverse concept, these complexities could be in the form of social sciences, economic patterns, cultural dynamism, while there are various dimensions to sustainable development today, poverty, terrorism and a deeper understanding of the complex dynamics of the human environment system within which businesses exist. The theories are lacking in the understanding that exists in building interconnectedness, interdependence and embeddedness at all levels of businesses and it can be improved only by focusing on human wellness.

\section{Conclusion}

Consumers everywhere are driven by their needs, in certain cases such as the BOP markets it could be just basic needs or overlapping needs, they are looking for products and services that can fulfill their needs while improving the quality of their lives, at prices they perceive affordable. As has been evidenced by several case studies on companies operating in BOP markets, affordable offerings through localized collaborative value partnerships providing socio economic progress will herald success for organizations. Thus in this Cockroach theory of organizational sustainability and scalability, like cockroach, business organizations should be highly alert and sense any situation that could be a danger or threat for survival, should have the tenacity to bear the loss and regrow lost opportunities, need to sustain through the tough times, have an open opportunity to tap the largest consumer base in the world, venture to serve BOP markets need to be armoured with a tough skin, for building large scales of businesses in emerging economies especially in the BOP sectors by digesting all shortcomings that can come along the way and use these as food to sustain, and to be as discreet as possible in a way that the communities perceive these businesses, people and offerings as one of their own by serving the BOP sector. Sustainability and scale is built around providing the best within available resources while making arrangements to provide continued value in the future as well.

\section{References}

[1] Prahalad, C. K., \& Hart, S. L. (1999). Strategies for the bottom of the pyramid: creating sustainable development. Ann Arbor, 1001, 48109.

[2] Prahalad, C. K. and Lieberthal, K. (1998) 'The end of corporate imperialism', Harvard Business Review, 76(4), 68-79.

[3] Prahalad, C. K., \& Hart, S. L. (2002). The Fortune at the Bottom of the Pyramid. Fortune + Business, Issue 26, pp. 4, https://people.eecs.berkeley.edu/ brewer/ict4b/Fortune-BoP.pdf Referred on 10th June, 2018.

[4] Simanis, E. (2011). Needs, needs, everywhere, but not a BoP market to tap. Next generation business strategies for the base of the pyramid, 103-126.

[5] Prahalad, C. K. (2006). The Fortune at the Bottom of the Pyramid. Pearson Education India.

[6] Prahalad, C. K., \& Hammond, A. (2002). Serving the world's poor, profitably. Harvard business review, 80(9), 48-59.

[7] Prahalad, C. K., \& Ramaswamy, V. (2004). The future of competition: Co-creating unique value with customers. Harvard Business Press.

[8] London, T., \& Hart, S. L. (2004). Reinventing strategies for emerging markets: beyond the transnational model. Journal of international business studies, 35(5), 350-370.

[9] Keerthan, R. \& Aithal, P. S. (2017). A 'Desi' Multinational - A Case Study of Hindustan Unilever Limited. International Journal of Case Studies in Business, IT and Education (IJCSBE), 2(1), 1-12. DOI: http://dx.doi.org/10.5281/zenodo.1147365.

[10] Aithal, P. S. (2017). An Effective Method of Developing Business Case Studies based on Company Analysis, International Journal of Engineering Research and Modern Education (IJERME), 2(1), 16-27. DOI: http://dx.doi.org/10.5281/ZENODO.400579.

[11] Aithal, P. S., (2017). ABCD Analysis as Research Methodology in Company Case Studies. International Journal of Management, Technology, and Social Sciences (IJMTS), 2(2), 40-54. DOI: http://dx.doi.org/10.5281/zenodo.891621 
[12] Raj, Keerthan and Aithal, P. S., Literature Review of Impact of Branding on Base of the Pyramid Markets with Special Reference to India (March 6, 2018). International Journal of Applied Engineering and Management Letters (IJAEML), 2(1), 43- 63. DOI: http://dx.doi.org/10.5281/zenodo.1189047.

[13] Raj, Keerthan and Aithal, P. S., (2018). Generating Wealth at the Base of the Pyramid - a Study Using ABCD Analysis Technique. International Journal of Computational Research and Development (IJCRD), 3(1), 68-76. DOI : http://doi.org/10.5281/zenodo.1205586.

[14] Raj, Keerthan \& Aithal, P. S. (2018). The Cockroach Theory for Sustainable and Scalable Organizational and Individual Growth. International Journal of Advanced Trends in Engineering and Technology, 3(1), 146-149. DOI : http://doi.org/10.5281/zenodo.1237899.

[15] Aithal, P. S. (2015). Concept of Ideal Business \& Its Realization Using E-Business Model. International Journal of Science and Research (IJSR), 4(3), 1267 - 1274, DOI : http://doi.org/10.5281/zenodo.61648.

[16] Aithal, P. S. (2015). Mobile Business as an Optimum Model for Ideal Business. International Journal of Management, IT and Engineering (IJMIE), 5(7), 146-159. DOI : http://doi.org/10.5281/zenodo.163880.

[17] Norberg, J \& Cumming, Graeme. (2008). Complexity theory for a sustainable future: conclusions and outlook. Complexity theory for a sustainable future. 227-293.

[18] http://www.wri.org/publication/next-4-billion/ accessed on May 16, 2018.

[19] Cyert, R. M., \& March, J. G. (1963). A behavioral theory of the firm. Englewood Cliffs, NJ, 2, 169-187. 